\title{
Marcação de caso e funções sintáticas em Asurini do Xingu
}

\author{
Case marking and syntactic functions in Asurini do Xingu
}

\author{
Antônia Alves PEREIRA* \\ Universidade Federal do Pará (UFPA)
}

\begin{abstract}
RESUMO: Este artigo apresenta resultados referentes à análise do sistema de marcação de caso em Asurini do Xingu, mostrando a sua importância na identificação de sintagmas nominais que desempenham as funções sintáticas sujeito e objeto no nível intraclausal. Na língua há duas classes de verbo: uma ativa e outra inativa. Essa divisão provoca uma cisão no sistema de caso da língua. Na estrutura ativa, existe um sistema nominativo-acusativo. Nesse sistema, prefixos da série I levam à identificação tanto de A quanto de $S$; já na estrutura inativa, surge o sistema cindido, Split-S. Nesse sistema, Sa e A são codificados da mesma forma, diferentemente de So e $\mathrm{O}$, que são codificados por pronomes pessoais. Mostra também que apenas a marcação de caso não seria suficiente para a identificação de sujeito e objeto em todos os contextos linguísticos, sendo necessário o uso de outros mecanismos, como ordem, referência cruzada e hierarquia de pessoa.
\end{abstract}

PALAVRAS-CHAVE: Morfossintaxe; Marcação de caso; Sujeito; Objeto

ABSTRACT: This article presents results referring to the analysis of the case marking system in Asurini do Xingu, showing the importance of this system in the identification of noun phrases that perform the subject and object syntax functions at the intra-clausal level. In the language there are two classes of verb: one active and one inactive. This division causes a split in the language case system. In the active structure, there is a nominative-accusative system. In this system, series I prefixes lead to the identification of both A and S; in the inactive structure, the Split-S system appears. In this system, Sa and A are encoded in the same way, unlike So and O, which are encoded by personal pronouns. It also shows that just the case marking would not be enough for the identification of subject and object in all linguistic contexts, requiring the use of others mechanisms, such as order, cross-reference and person hierarchy.

KEYWORDS: Morphosyntax; Case marking; Subject; Object

* Doutora em Linguística e professora na Universidade Federal do Pará, Faculdade de Letras. E-mail: antonia@ufpa.br 


\section{Introdução}

O estudo das funções sintáticas nucleares constitui um ponto de partida fundamental na descrição e análise de uma língua. $O$ 'termo funções sintáticas nucleares' compreende as funções sujeito e objeto, ou seja, aquelas funções que apresentam uma relação mais estreita com o núcleo verbal. As propriedades linguísticas largamente utilizadas em tipologia para a identificação dessas funções são: marcação de caso, referência cruzada e ordem dos constituintes.

Esse trabalho tem por meta mostrar como funciona o sistema de marcação de caso nas orações independentes, em Asurini do Xingu, e como esse sistema se relaciona com as outras propriedades formais na identificação de sintagmas nominais (SNs) que funcionam como sujeito e como objetos direito e indireto. Essa língua pertence à família Tupi-Guarani, está inserida no grupo IV, conforme classificação interna proposta para família por Rodrigues e Cabral (2002). O povo asurini do Xingu vive no município de Altamira, estado do Pará, sendo a população composta por aproximadamente 170 pessoas.

O artigo parte dos pressupostos teóricos da linguística tipológico-funcional sobre as concepções de marcação de caso, referência cruzada e ordem nas línguas em geral e segue para a descrição e análise do funcionamento desses mecanismos na identificação dessas funções em Asurini do Xingu. Autores como Dixon (1994), Palmer (1994), Comrie (1981), Givón (1984), Payne (1997) Geenberg (1963), entre outros, fundamentaram teoricamente as escolhas feitas para a apresentação da descrição do fenômeno supramencionado na língua Asurini do Xingu.

Os dados utilizados foram coletados in locu, por nós, ao longo de nossas pesquisas junto ao povo asurini e são provenientes de narrativas míticas, experiência pessoal e conversas em contexto natural, sendo, posteriormente, testados junto aos falantes para fins de descrição.

$\mathrm{O}$ artigo está dividido em três partes. Na primeira parte, tratamos de aspectos tipológicos relacionados à marcação de caso, à referência cruzada e à ordem nas línguas em geral. Na segunda parte, apresentamos algumas considerações sobre o uso do morfema -a - Ø na família tupi-guarani e em Asurini do Xingu. Na terceira parte, analisamos a marcação de caso, a referência cruzada e a ordem como mecanismos que 
atuam na identificação das funções sintáticas nucleares na língua. Finalmente, na última parte, apresentamos as considerações finais acerca da temática marcação de caso e funções sintáticas nucleares na língua.

\section{Marcação de caso e funções sintáticas nucleares na perspectiva tipológico-funcional}

Nesta parte, exploramos as propriedades fundamentais responsáveis por estabelecer as relações sintáticas nucleares nas línguas em geral, ou seja, a relação que se estabelece entre o núcleo verbal e os sintagmas que desempenham as funções sujeito e objeto (s), bem como, características definidoras dos sintagmas nominais (SNs) que atuam como Sujeito e como Objeto em uma sentença independente, apesar de claro para nós que não existe um fenômeno morfossintático único que identifique de forma absoluta e consistente cada uma das relações gramaticais translinguisticamente. Conforme (Payne, 1997), essas propriedades são de natureza formal, manifestando-se por meio da morfologia, da sintaxe ou da morfossintaxe das línguas.

As línguas apresentam estratégias variadas para identificar funções sintáticas. As propriedades formais que são comumente utilizadas para identificar as funções gramaticais são: a) marcação de caso; b) marcação referencial no participante, conhecida também como concordância e c) ordem dos constituintes.

De acordo com Comrie (1981) e Dixon (1994), os papéis gramaticais S, A, O são primitivos e universais, isto é, são encontrados em todas as línguas, e identificados a partir das relações que se estabelecem entre argumento e verbo em um nível da estrutura linguística. Conforme Dixon (1994, p. 6), “All languages distinguish between clauses that involve a verb and one core noun phrase (intransitive clauses) and those that involve a verb end two or more core NPs (transitive clauses, including ditransitive as a subtype) $)^{1}$. Dessa maneira, S é o argumento único de uma sentença, cujo predicado é intransitivo, A é o argumento controlador, o mais agentivo de uma sentença com

\footnotetext{
${ }^{1}$ Todas as línguas distinguem entre orações que envolvem um verbo e um sintagma nominal núcleo (orações intransitivas) e aquelas que envolvem um verbo e dois ou mais sintagmas nominais núcleos (orações transitivas, incluindo ditransitivo como um subtipo) (Tradução nossa)
} 
predicado transitivo, enquanto $\mathrm{O}$ codifica o argumento mais afetado de uma sentença transitiva.

A partir da maneira como as línguas organizam essas funções, ou seja, a partir da maneira como esses papéis se relacionam, as línguas exibem diferentes alinhamentos sintáticos. Tipologicamente, distinguem-se cinco tipos de alinhamentos sintáticos: I) ergativo-absolutivo, II) nominativo-acusativo III), ativo-estativo, IV) neutro e V) tripartido, sendo os dois primeiros os mais recorrentes nas línguas. De acordo com Comrie (1981, p. 125), o sistema tripartido é raro, e o neutro, por apresentar as mesmas marcas para $\mathrm{S}$, A e $\mathrm{O}$, necessita de outros mecanismos para identificar eficazmente as funções sujeito e objeto.

O Sistema nominativo-acusativo é aquele em que $\mathrm{S}$ se comporta igual a $\mathrm{A}$. Nesse sistema, o nominativo é o caso associado aos papéis $\mathrm{S}$ e A, e o acusativo ao papel O. Dixon (1994) se refere à acusatividade nos seguintes termos: "one case (nominative) marks both intransitive and transitive subject, with another case (accusative) being employed for transitive object". (p.1).

No Sistema ergativo-absolutivo, em conformidade com Dixon (op. cit.), S se comporta da mesma forma que $\mathrm{O}$ e diferente de $\mathrm{A}$, sendo o ergativo o caso atribuído ao sujeito de verbo transitivo (A), e o absolutivo o caso atribuído ao objeto (O) e ao sujeito de verbo intransitivo $(\mathrm{S})$.

O sistema neutro, diferentemente dos dois anteriores, atribui a mesma marca morfológica - que pode ser nula - a S, A e O. Por apresentar a mesma forma para essas três funções, Comrie (1981) não o considera um sistema eficiente na distinção desses três papéis primitivos.

No sistema Tripartido, S, A e O recebem marcas morfológicas distintas. Comrie (1981, p. 126) também não o considera um sistema de marcação de caso eficiente, já que novamente não possibilita a distinção eficaz entre $\mathrm{A}$ e $\mathrm{O}(\mathrm{P})^{2}$.

Dixon (1994) discute os casos em que as línguas juntam os alinhamentos nominativo-acusativo com o ergativo-absolutivo, formando um novo alinhamento.

\footnotetext{
${ }^{2}$ The tripartite system is unnecessarily explicit, since in addition to distinguishing A from $\mathrm{P}$, it also distinguishes each of these from $S$, even though $S$ never cooccurs with either of the other two. The A/P $\mathrm{S}$ system is, from a functional viewpoint, singularly inefficient, failing to make the most useful distinction (between $\mathrm{A}$ and $\mathrm{P}$ ), and making a useless distinction (between $\mathrm{A}$ and $\mathrm{S}$, likewise between $\mathrm{P}$ and $\mathrm{S}$ ). COMRIE, 1981, p. 126)
} 
Chama essa junção cisões de caso, descrevendo-as como sistemas cindidos. De acordo com esse autor (Dixon, 1994, p. 70), essas cisões são condicionadas pela natureza semântica do verbo principal, pela natureza semântica do sintagma nominal, pelas categorias tempo, aspecto e modo e, finalmente, pela relação entre oração principal e subordinada. As línguas podem fazer uso de um ou mais de um desses parâmetros na cisão de caso.

A partir de suas discussões, Dixon apresenta dois tipos de sistemas cindidos: cisão-S, ou Split-S, e Fluid-S. Conforme esse autor, na cisão-S, aqueles S que são semanticamente semelhantes a A (exercendo controle sobre a atividade) serão Sa, marcados como $\mathrm{A}$, e aqueles $\mathrm{S}$ que são semanticamente semelhantes a $\mathrm{O}$ (sendo afetados pela atividade) serão So, marcados como O.

Apesar de o sistema Split-S e o sistema Fluid-S apresentarem propriedades em comum: uma cisão no S- eles apresentam propriedades distintivas que fazem com que sejam dois sistemas diferentes. Em conformidade com o autor acima citado, no sistema Split-S a marcação de caso ou referência cruzada será feita sempre da mesma forma, independentemente da semântica de uma instância particular de uso; já no sistema Fluid-S, o sujeito intransitivo pode ser marcado como Sa (ou seja, como A) ou como So (ou seja, como O), dependendo da semântica de uma determinada instância de uso.

\section{Considerações sobre o morfema -a $\infty$ - $\emptyset$ na família tupi-guarani e em Asurini do Xingu}

As reconstruções feitas para o Proto-Tupi-Guarani mostram que, na protolíngua, havia um conjunto de sufixos que marcava as funções das palavras na cláusula. Esse conjunto de sufixos vem sendo tratado por uma longa tradição de linguistas, que trabalham com línguas da família tupi-guarani, como marcadores de caso.

Segundo Rodrigues (1996, p. 60), o sufixo do caso argumentativo -a $\infty-\varnothing$, em Tupinambá, compreendia todas as principais funções gramaticais, como as de sujeito de verbo intransitivo e transitivo, de objeto direto, de possuidor e de objeto de posposição.

Seki (2000, p.107) analisa o morfema -a $\infty$ - , no Kamaiurá, como marcador de funções sintáticas nucleares. Tanto na análise de Rodrigues (1996) quanto na de Seki 
(2000), fica evidenciada a função predicativa que o nome desempenha quando está desprovido de morfologia flexional.

Queixalós (2001), seguido por Rose (2003, p. 117), analisa o referido morfema, na língua Émérrillon, como um sufixo referencial, dado o fato de sua distribuição não incluir afixação sobre um predicado de tipo equativo. Percebemos, dessa forma, que apesar dos tratamentos diferenciados dados a esse morfema nessas análises, há em comum em todas elas o fato de esse morfema ser tratado como uma marca que possibilita uma raiz, que tem a função primária de predicar, desempenhar funções tipicamente nominais. Em outras palavras, o acréscimo do morfema -a $\infty$ - $\varnothing$ torna um elemento predicador em nominal.

Em Asurini do Xingu, o sufixo -a $\infty$ - $\varnothing$ está em processo de radiciação, isto é, juntando-se ao radical dos nomes, consequentemente, deixando de exercer a função de marcador de caso, conforme terminologia adotada por Rodrigues (1966). Na língua, não há diferença formal entre um nome desempenhando as funções de sujeito, objeto de verbo e de posposição, e um nome que se encontre na forma citacional ou no vocativo. Dito de outra forma: parece não existir distinção formal entre um nome que está predicando e um nome que está sendo usado no sentido referencial. O sufixo -a aparece no Asurini do Xingu junto à raiz dos nomes terminados em consoantes, como se vê nos dados a seguir

a) Forma citacional

(01) ure-ramũ mama'e r-enũma amiramu ure mama'e t-upava dja ure r-upava 1Pl-Atr Gn Rel-nome agora 1Pl Gn 3Indf-rede Part 1Pl Relrede

'Enquanto nós damos nome as nossas coisas agora: rede, nossa rede...

b) Vocativo

$$
\begin{aligned}
& \text { ma'e pe gy u-juka muajva } \\
& \text { Q } \quad 3 P 1 \quad \text { 3-matar } \mathrm{Npr} \\
& \text { 'O que eles matam, Muajva?' }
\end{aligned}
$$


c) Sujeito de sentença intransitiva

(03) aka u-kaj

casa 3-queimar

'A casa queimou'

d) Sujeito de sentença transitiva

(04) tapi'ira a- dje-mujn

anta 1sg- Refl-correr atrás

'Anta correu atrás de mim'

e) Objeto direto

(05) yvyrapara u-apa

arco 3-fazer

'Ele fez arco'

Outro fator que corrobora nossa análise é o fato de não haver distinção entre uma oração equativa na forma afirmativa e um $\mathrm{SN}$ : ambos se apresentam com o -a no núcleo nominal.

(06) ene ureraryva

2 sg chefe

'Você é (o) chefe'

(07) ureraryva u-kyt

chefe 3-dormir

'O chefe dormiu'

Como percebemos, em (06) o nome 'ureraryva' está sendo usado na função predicativa, e em (07), numa função argumentativa, entretanto, não há distinção formal 
nele. A função predicativa não é compatível com o uso do morfema -a nas línguas em que ele é usado para assinalar distinção entre funções argumentais e predicativas, como no Kamaiurá, por exemplo.

Entretanto, no Asurini do Xingu, em alguns contextos linguísticos, há o deslocamento do sufixo - a do radical do nome para figurar imediatamente depois de alguns morfemas, conforme os dados (08), (09) e (10). Além disso, uma raiz verbal, após ser nominalizada exige a presença desse morfema imediatamente depois do nominalizador, conforme consta no dado (11), à exceção de nominalização pelo acréscimo de -ma'e (Pereira 2010). Isso demonstra, como já dito, que esse morfema ainda está em processo de radiciação, isto é, que esse morfema não está totalmente incorporado à raiz de natureza nominal. Diante do fato, de nas línguas da família TupiGuarani, a função primeira do nome ser predicar, conforme tratado acima, e de a função de um nominalizador ser atribuir uma função nominal a uma dada categoria, desempenhando essa categoria -após receber esse nominalizador- funções tipicamente nominais, fica evidente que o sufixo - a ainda não perdeu totalmente sua função na língua.

(08) dje r- erakwat-er -a

1sg Rel-marido -Pas -N.

'Aquele que foi meu marido'

(09) medju-rum-a

beiju-Fut-N

'O que será beiju'

(10) ga r-ak -um-a

3sg.Mas Rel-casa-Fut-N

'A que será casa dele'

(11) myra n-u-kuav-i pene kyt-av-a

Npr neg-3-saber-neg 2sg dormir-Nom-N

'Myra não sabe o lugar onde você dormiu' 
Além desses casos, há um outro que merece atenção especial que é o fato de um descritivo $^{3}$, para desempenhar função atributiva, precisar do morfema -a. Os dados abaixo ilustram o que dissemos

$\begin{array}{ll}\text { (12) aka } & \text { i-djup } \\ \text { casa } & \text { Rel-amarelo }\end{array}$

'A casa é amarela'

(13) aka i-djuv -a u-at

casa Rel-amarela-N 3-cair

'A casa amarela caiu'

(14) ene r-akup

2sg Rel-quente/febril

'Você está quente/febril'

(15) dje r- akuv -a a-mu'uk

1sg Rel-quente-N 1sg-banhar-se

'Eu febril tomei banho'

Os dados (12) e (14) mostram os descritivos na função predicativa e os exemplos (13) e (15) na função atributiva. Nos dois primeiros, os descritivos aparecem sem a marcação do morfema -a; e, nos dois últimos, esse morfema aparece evidenciando que os nomes estão na função atributiva. Casos como esses nos levam a pensar que em estágios não muito distantes, esse morfema tenha marcado as funções sintáticas nucleares na língua, ou seja, o nome necessitava de um morfema especial, -a, para desempenhar uma função que é tipologicamente conhecida como pertencente a ele: servir de argumento.

Dessa forma, a análise sincrônica dessa língua sugere uma mudança em curso do morfema -a, corroborando com a análise de Queixalós (2001, p. 116-117), que propõe

\footnotetext{
${ }^{3}$ O termo descritivo refere-se, no Asurini do Xingu, a um subtipo de verbo.
} 
dois estágios para as línguas Tupi-Guarani: um estágio primeiro em que todas as raízes lexicais teriam vocação predicativa. Nesse contexto, era o sufixo -a que permitia a referência a partir daquelas raízes lexicais que não tinham capacidade de referenciar sozinhas. Assim, o morfema -a se anexaria à raiz que tinha como função primeira predicar, fazendo com que ela passasse a desempenhar funções argumentativas, como sujeito e objeto. Por outro lado, o morfema -a se encontrava também sobre um predicado numa relação equativa, não tendo mais apenas a função translativa, mas também a capacidade de fazer referir o constituinte sobre o qual ele se afixara. A partir desse momento, estaria se iniciando o segundo estágio: o morfema deixando de atuar no contexto pós-vocálico em algumas línguas, desaparecendo em outras e continuando a marcar todas as funções que marcava no primeiro estágio em outras línguas da família.

Com base nessas considerações, percebemos que apenas esse mecanismo, marcação com o morfema -a, por si, não é um recurso suficiente para identificar eficazmente as funções sintáticas sujeito e objeto em Asurini do Xingu. Sendo assim, passemos à análise de outros mecanismos: marcação de caso, referência cruzada e ordem.

\section{Marcação de caso e funções sintáticas nucleares em Asurini do Xingu}

Funções sintáticas nucleares compreendem àquelas desempenhadas por sujeito e objeto(s) em uma língua, como vimos acima. De acordo com Dixon (1994), são maneiras de codificar as relações sintáticas nucleares em um sintagma nominal S, A, ou O: a) flexão de caso, b) partículas e adposições e c) referência cruzada, caso em que um verbo ou um auxiliar verbal pode incluir afixos que forneçam informações sobre a pessoa e/ou número e/ou gênero etc. em concordância com um sintagma nominal

Em Asurini do Xingu, ocorre o uso de mais de um desses recursos para a identificação dessas funções, dependendo da situação linguística. A seguir discutimos os recursos utilizados na identificação dessas funções. 


\subsection{Referência cruzada e sistema nominativo-acusativo}

A referência cruzada é entendida como uma propriedade formal, cuja função é carregar informações morfológicas, como pessoa, número e gênero, que se originam em outro ponto da estrutura linguística. Por exemplo, no verbo português, por meio desse mecanismo, é possível se recuperar informações sobre número e pessoa do SN que desempenha a função de sujeito, sendo o principal critério para identificar o argumento nuclear mais subjetivo nessa língua. Em conformidade com Dixon (1994, p. 40), 'A verb or verbal auxiliary may include bound affixes etc., which provide information about the person and/or number and/or gender etc. of NPs in certain syntactic functions, 4

A referência cruzada em Asurini do Xingu, a partir da afixação de um prefixo da série I ao verbo ativo, carrega informações sobre o número e a pessoa em que se encontra o SN que figura como sujeito $\mathrm{S}$ ou A. Por outro lado, na língua, encontra-se uma série de pronomes pessoais que atua na codificação de SNs que desempenham funções $\mathrm{O}$ e So, conforme veremos adiante.

Quadro 1: pronomes pessoais e prefixos da série I

\begin{tabular}{|l|l|l|}
\hline Pessoas & Pronomes pessoais & Prefixos da série I \\
\hline $1^{\text {a }}$ p. sg & dje & a- \\
\hline $2^{\text {a }}$ p. sg & ene & ere- \\
\hline $1^{\text {a }}$ p. incl. & djane & txa- \\
\hline $1^{\text {a }}$ p. excl. & ure & uru- \\
\hline $2^{\text {a }} \mathrm{pl}$. & pene & pe- \\
\hline $3^{\text {a }}$ p. sg/pl & ga (mas.), ẽ (fem.) / gy & u- \\
\hline
\end{tabular}

Fonte: Pereira (2020)

Os dados abaixo ilustram como funciona o sistema de referência cruzada na língua:

\footnotetext{
${ }^{4}$ Um verbo ou auxiliar pode ter afixos etc., que forneçam informações sobre a pessoa e/ou número e/ou gênero etc. de SNs em certas funções sintáticas.
} 
a) sujeito de verbo transitivo

(16) djawara a-etxak

$$
\begin{array}{ll}
\text { onça } & 1 \text { sg-ver } \\
\mathrm{O} & \text { a-verbo }
\end{array}
$$

'(eu) Vi a onça'

(17)

$$
\begin{array}{lll}
\tilde{\mathrm{e}} & \text { mani'aka } & \text { u-py’yk } \\
\text { 3sg.Fem } & \text { mandioca } & \text { 3-pegar }
\end{array}
$$

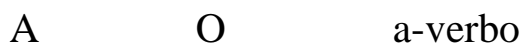

'Ela pegou mandioca'

(18)

$\begin{array}{ccc}\text { myra } & \text { ga } & \text { u-djuka } \\ \text { Npr } & \text { 3sg. Mas } & \text { 3-matar } \\ \text { A } & \text { O } & \text { a-verbo }\end{array}$

'Myra o matou'

b) sujeito de verbo intransitivo
(19) kunumi u-kyt
menino 3-dormir
S

$$
\text { s-verbo }
$$
'O menino dormiu'

De acordo com esses dados, podemos visualizar o padrão nominativo-acusativo para essa língua nesse nível. Conforme Dixon (1994), o sistema nominativo-acusativo é obtido da referência cruzada com o mesmo afixo representando $\mathrm{S}$ ou $\mathrm{A}$, e outro tipo de afixo representando a referência O. Conforme o autor:

The patterning of bound pronominal affixes in the verbal word can be taken as evidence of intra-clausal accusativity or ergativity, just like the patterning of case inflections. If a certain affix cross-references an NP that is in $\mathrm{S}$ or A function, with a different affix referring to an NP that is in $\mathrm{O}$ 
function, then the language can be characterised as 'nominative accusative' at this level ${ }^{5}$. (Dixon, 1994, p. 42)

Dessa maneira, a referência cruzada usada para a identificação de S, A e a codificação do objeto por meio de pronomes pessoais, assinalando, portanto, $\mathrm{S}=\mathrm{A}$, e diferente de $\mathrm{O}$, configura um padrão nominativo-acusativo no nível intraclausal, na estrutura ativa da língua Asurini do Xingu.

Em (20) e (21) u- é correferente com os SNs que desempenham a função de sujeito, e em (24), o pronome ga desempenha a função de objeto direto.

$\begin{array}{ccc}\text { Myra } & \text { djawara } & \text { u-etxak } \\ \text { Npr. } & \text { onça } & \text { 3-ver } \\ \text { O } & & \text { a-V }\end{array}$

'Myra viu a onça'

$$
\begin{array}{lr}
\text { kunumi } & \text { u-kyt } \\
\text { menino } & \text { 3-dormir } \\
\mathrm{S} & \text { s-verbo } \\
\text { 'O menino dormiu' }
\end{array}
$$

$$
\begin{array}{ll}
\text { ga } & \text { a- etxak } \\
\text { 3sg.Mas } & \text { 1-ver } \\
\text { O } & \text { a- } \quad \text { V }
\end{array}
$$

'Eu o vi'

O prefixo da série I, anexado ao verbo pode estabelecer concordância com um SN expresso por nome, por um SN expresso por pronome pessoal, em função livre, ou mesmo ser referência de um SN que não está expresso na oração, analogamente ao que se tem em português com os sufixos verbais que expressam número e pessoa no verbo, como em Maria e João comeram ontem, nós comemos ontem, comemos ontem. Dessa forma, o uso de prefixo da série I junto ao verbo é uma regra geral no sistema ativo da

\footnotetext{
5 A padronização de afixos pronominais ligados ao verbo pode ser tomada como evidência de acusatividade ou ergatividade intraclausal, assim como a padronização das flexões do caso. Se um determinado afixo faz referência cruzada a um SN que está em função $\mathrm{S}$ ou A, com um afixo diferente referindo-se a um SN que está exercendo a função $\mathrm{O}$, então essa língua pode ser caracterizada como 'nominativo- acusativa ' neste nível (Dixon, 1994, p. 42) (Tradução nossa)
} 
língua, estando o SN sujeito explícito ou não na sentença, quando inoperante a hierarquia de pessoa e quando não há o uso de morfema portmanteau.

Em Asurini do Xingu, a sentença que exibe objeto indireto em sua estrutura argumental o faz marcando-o diferentemente de objeto direto. O objeto direto é codificado por pronomes pessoais e por nominais, sem nenhuma marca especial; já o objeto indireto caracteriza-se por sua função sintática ser demarcada e diferenciada de outras funções pelo uso de posposição, isto é, o objeto indireto é formado pelos mesmos elementos que formam o objeto direto, contudo, distingue-se deste pelo uso de posposição que assinala ser essa função sintática diferente da de objeto direto. Em ambos estão ausentes marcas de concordância com o verbo da oração.

dje ipira a-mana antonia upe

1sg peixe 1-dar Npr Posp.

'Eu dei peixe à Antônia'

(24) ipira pe-rut ga upe

peixe 2pl-trazer 3sg Posp

'Vocês trouxeram peixe para ele'

Dessa forma, a maneira de codificar o objeto indireto, nesta língua, está em conformidade com o que vem sendo discutido na tipologia. De acordo com essa abordagem, as línguas que exibem três argumentos em sua estrutura argumental distinguem a marcação do objeto indireto da marcação do objeto direito.

Como podemos perceber, a partir dos exemplos, a concordância em Asurini do Xingu revela-se como um mecanismo eficiente na identificação de sujeito e objeto. Como vimos, no verbo, via de regra, aparece apenas um afixo que permite identificar o sujeito da oração, através da referência cruzada.

Apesar de ser um critério altamente funcional na identificação das funções sintáticas nucleares, a concordância pode não ser completamente segura em algumas circunstâncias, mesmo naquelas línguas em que atua como principal critério na identificação dos SNs sujeito e objeto. Em casos como esses, a língua, normalmente, dispõe de outro(s) critério(s) que suprem a lacuna. Em português, por exemplo, esse 
critério pode falhar quando os sintagmas nominais sujeito e objeto encontram-se na mesma pessoa e número. Em exemplos como Mariana pintou Pedro e Mariana pintou o gato, usando apenas o critério concordância, fica difícil a identificação do SN sujeito e, consequentemente, do SN objeto na língua, já que ambos se encontram na terceira pessoa do singular, sendo necessário que se se recorra a outro(s) critério(s) para saber quem pintou quem. Em ambos os exemplos, pode-se recorrer ao critério sintático ordem. Sabemos que, em português, a ordem preferencial é SVO. Assim o sintagma nominal que figura antes do verbo por esse critério é SN sujeito; já no segundo exemplo, além do critério ordem, pode-se fazer uso do critério semântico, pois, na hierarquia para a identificação de sujeito, o traço [+humano] prevalece sobre o [humano]. Em um exemplo como Mariana gato pintou, o critério ordem seria de pouca relevância, sendo o critério semântico o mais importante.

Há ainda, em Asurini do Xingu, dois recursos importantes que atuam na identificação de argumentos nucleares na língua, mas que não serão objeto de análise aqui dada a extensão do assunto: morfema portmanteau e hierarquia de pessoa. Esse morfema marca cumulativamente sujeito e objeto na língua; já na hierarquia de pessoa, quando é rompida a hierarquia de agentividade natural da língua em que 1>2>3, apenas o objeto é codificado junto ao verbo com a série pessoal correspondente. Esse tipo de hierarquia, conforme Hewson (1991), tem se mostrado altamente icônica, pois sua existência não estaria baseada unicamente na agentividade natural da $1^{\mathrm{a}}$ pessoa sobre a $2^{\mathrm{a}}(1>2)$, como foi afirmado por Silverstein (1976), por Comrie (1978) e por Dixon (1979), mas também no papel central ou ponto de vista estabelecido pelo participante do ato de fala, o qual pode pôr um papel substancial em algum discurso ${ }^{6}$. A seguir exemplos:

uru-py’ yk

1.2- segurar

A.O-V

'Segurei você'

\footnotetext{
${ }^{6}$ Dada a natureza desse trabalho, essa discussão não parece relevante aqui.
} 
'Ele me viu'

Conforme podemos ver no dado (25), o prefixo portmanteau uru- codifica cumulativamente A e O. Já o dado (26) ilustra a situação em que foi rompida a hierarquia natural da língua, sendo codificado na sentença transitiva apenas o objeto.

\subsection{Sistema cindido em Asurini do Xingu}

A língua Asurini do Xingu manifesta uma cisão-S. Nesse tipo de cisão, em conformidade com Dixon (1994, p. 70), aplica-se a S a mesma base semântica contrastiva aplicada a $\mathrm{A}$ e a $\mathrm{O}$ nas sentenças transitivas. Aqueles $\mathrm{S}$ que são semanticamente semelhantes a A (exercendo controle sobre a atividade) serão Sa, marcados como $\mathrm{A}$, e aqueles $\mathrm{S}$ que são semanticamente semelhantes a $\mathrm{O}$ (sendo afetados pela atividade) serão então, marcados como $\mathrm{O}$.

Em Asurini do Xingu, encontram-se duas classes de verbos: uma ativa e uma estativa, conforme (Pereira 2009). Na classe ativa, os argumentos S e A funcionam da mesma maneira, sendo $\mathrm{O}$ expresso de forma distinta, conforme vimos acima, no sistema pessoal da língua. Entretanto, constatamos mecanismos distintos de codificação desses argumentos quando estão diante da classe de verbos estativa ou inativa. Nessa situação, o argumento S é cindido, dividindo-se em dois subtipos de argumentos: Sa e So. Está configurada a cisão-S na língua. $\mathrm{O}$ alinhamento nominativo-acusativo que ocorre no sistema ativo da língua é substituído por um alinhamento cindido: cisão-S, Split-S, revelando ser o Asurini do Xingu, uma língua de estrutura ativo-estativa, conforme terminologia adotada por Klimov (1974, apud Seki 2000), já que esse autor analisa esse sistema baseado na semântica verbal, partindo da oposição ativo x estativo.

Dessa forma, o sujeito de um verbo intransitivo (Sa), como -vevuj 'nadar' funciona com prefixos da série I da forma que o sujeito do verbo transitivo (A), como djuka; já o sujeito de um verbo descritivo (So), como -upi'a 'estar grávida', é 
codificado da mesma forma que $\mathrm{O}$ em sentenças transitivas, e ao verbo é anexado um prefixo relacional Rel-. Os exemplos abaixo ilustram essa configuração na língua.

a) Verbo transitivo

$(27)$

$\begin{array}{ll}\text { ga } & \text { a- etxak } \\ \text { 3sg.Mas } & \text { 1-ver } \\ \text { O } & \text { a- } \quad \text { V }\end{array}$

'Eu o vi'

(28) djawara u-etxak

onça 3-ver

$\mathrm{O} \quad \mathrm{a}-\mathrm{V}$

'Ele viu a onça

b) Verbo intransitivo ativo

(29) a-vevuj

1sg-nadar

$\mathrm{Sa}-\mathrm{V}$

'Eu nadei'

c) Verbo intransitivo estativo

(30) dje r- upi'a

$1 \mathrm{sg}$ Rel- estar.grávida

So Rel- Ve

'Eu estou grávida'

O dado (27) mostra ga funcionando como objeto, já o dado (30) exibe o pronome pessoal dje, da mesma série que ga, funcionando como So. Enquanto que os dados (30) e (29) mostram que So e Sa referenciam sujeito de formas distintas: 
enquanto a primeira pessoa sujeito de So é codificada com o pronome pessoal dje, com o prefixo relacional afixado ao verbo, a primeira pessoa de Sa é referenciada pelo prefixo a-. Os dados (28) e (29) mostram que Sa e A marcam sujeito da mesma forma, isto é, com a mesma série de marcadores de pessoa, via referência cruzada.

Conforme podemos observar a partir dos dados, a cisão-S configura-se como condicionada pela semântica que envolve os tipos verbais que esculpem a estrutura argumental da sentença no nível intraclausal.

Esse tipo de padrão, finalmente, ilustra aquela situação, em que há, na visão de Palmer (1994), uma mesclagem entre os sistemas acustativo e ergativo das línguas. Conforme o autor:

\begin{abstract}
Some languages are ergative in one respect, but accusative in another; a language may even have ergative noun morphology ( $\mathrm{S}$ and $\mathrm{P}$ have the same marking on the noun), but accusative verbal agreement ( $\mathrm{S}$ and $\mathrm{A}$ have the same markers on the verb) (PALMER,1994, p. 14. ${ }^{7}$
\end{abstract}

Dados como esses do Asurini do Xingu mostram a grande importância da semântica na definição das categorias gramaticais em uma língua, demonstrando que semântica e gramática andam juntas, sendo a primeira um recurso extremamente últil para as distinções gramaticais. Dessa forma, uma abordagem linguística que despreze a semântica não merece prosperar dentro de uma perpectiva que considere a língua como intrumento de interação social e forma de expressão de seus falantes. O sistema Split-S em línguas da familia tupi-Guarani constitui uma prova bastante significativa da influência da semântica na definição das classes gramaticais nessa família.

\title{
3.3 A ordem dos constituintes em Asurini do Xingu
}

A ordem dos constituintes pode atuar (i) como o principal meio utilizado por uma língua para marcar função sintática ou (ii) ser apenas mais um recurso ao lado de outro(s). Tipologicamente, as línguas do segundo tipo tendem a apresentar a ordem dos constituintes relativamente livre, embora possam, por vezes, muitas línguas desse grupo

\footnotetext{
7 Algumas línguas são ergativas em um aspecto, mas acusativas em outro; uma língua pode até ter morfologia nominal ergativa ( $\mathrm{S}$ e P têm a mesma marcação no nome), mas podem ter a concordância verbal acusativa (S e A terem os mesmos marcadores no verbo) (PALMER, 1994, p. 14.) (Tradução nossa)
} 
apresentar ordem rígida de constituintes. Entretanto, cabe destacar que mesmo naquelas línguas para as quais a ordem dos constituintes é rígida, é possível que haja flutuações em seus usos, dependendo dos propósitos comunicativos de seus usuários. Dessa forma, uma língua é mais que estrutura, é instrumento de interação social, estando a serviço de seus falantes, como instrumento de performance.

Greenberg (1963) constatou que a ordem dos constituintes sujeito, objeto e verbo influenciava diretamente outros constituintes nas línguas. Essa constatação o levou à predição de que as línguas do mundo apresentavam certas características em comum. Partindo dessa ideia, ele criou padrões linguísticos com base no enfoque generalizante, vislumbrando regularidades entre as línguas que apresentavam a mesma ordem dos constituintes. Disse, por exemplo, que as línguas do tipo SOV tendiam a ter posposições e o genitivo quase sempre ocorrer depois do nome; já as línguas que apresentavam ordem básica SVO, como o português, tendiam a apresentar preposição e o genitivo ocorrer quase sempre depois do nome possuído.

Conforme as pesquisas de Greenberg (1963), as línguas do mundo podiam apresentar as seguintes ordens possíveis: SOV, SVO, VSO, VOS, OVS, OSV, sendo os quatro primeiros tipos mais recorrentes e os dois últimos aparecendo apenas como ordens possíveis, lógicas. Greenberg afirma que quando se trata de orações declarativas a ordem mais recorrente é quase sempre uma em que o sujeito é posicionado antes do objeto.

Mithun (1987) questiona a importância da ordem básica dos constituintes para a descrição de todas as línguas. Ela sustenta que nas línguas Cayuga, Ngandi e Coos as posições dos constituintes nominais são aparentemente determinadas, em grande parte, por fatores pragmáticos.

Na língua Asurini do Xingu, os constituintes sujeito, verbo e objeto figuram em mais de uma ordem na sentença. A razão para isso está relacionada ao fato de as construções linguísticas serem regidas também por fatores pragmáticos. Contudo, a ordem básica preferencial dos constituintes é SOV. A língua segue em grande parte as generalizações tipológicas previstas para línguas de ordem verbo-final, estando em conformidade com a maior parte dos correlatos propostos para esse padrão.

$\begin{array}{lll}\text { manuka } & \text { i } & \text { u-py'yk } \\ & \text { pira } & \end{array}$




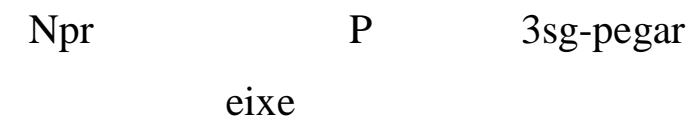

'Manuca pegou peixe'

(32) tata e- petek

fogo 2sg.Imp- abanar

'Abane o fogo!'

(33) Myra r-uva u-manu

Npr Rel-pai 3sg-morrer

'O pai de Myra morreu'

Conforme se pode observar nos dados acima, o SN mais próximo ao verbo desempenha a função sintática de objeto em sentenças transitivas e sujeito em sentenças intransitivas. A alteração na ordem dos constituintes modifica as funções dos SNs e, consequentemente, a significação da sentença.

(34) kudjema'e maja u-djuka

homem cobra 3-matar

'O homem matou a cobra

(35) maja kudjema'e u-djuka

Cobra homem 3-matar

'A cobra matou o homem'

Apesar disso, mesmo o critério ordem demonstrando-se eficiente, per si, na identificação dessas funções, o critério concordância continuou atuante, levando à identificação do sujeito da sentença por meio do afixo responsável pela referência cruzada aglutinado ao verbo.

Outros casos demonstram que apenas o critério ordem não seria suficiente para a identificação de sujeito e objeto nas sentenças. Exemplos disso são encontrados nos casos em que há rompimento da hierarquia de pessoa, uso de morfema portmanteau e 
nos casos em que o falante usa uma ordem menos marcada na língua com a finalidade de atingir propósitos comunicativos.

Dessa forma, em Asurini do Xingu, a ordem demonstra ser um importante recurso na identificação de sujeito e objeto, mas divide o espaço com outros critérios, especialmente, o critério referência cruzada.

Nas línguas que apresentam a marcação de caso como o principal recurso na identificação de sujeito e objeto, as palavras de qualquer sentença podem ser rearranjadas em mais de uma ordem, sem que haja quaisquer mudanças de significado. Isto contrasta com línguas em que a ordem é o principal recurso utilizado na identificação de sujeito e objeto, pois a alteração na ordem altera também a função dos sintagmas e, consequentemente, o significado nas sentenças. O português, ao lado do critério concordância, faz uso também da ordem dos constituintes na delimitação de funções sintáticas. Dessa maneira, dependendo da posição que um sintagma nominal ocupe na sentença, há alteração no significado de construções. Exemplos como $O$ menino matou a cobra e A cobra matou o menino ilustram esse caso. Apenas a troca de posição do primeiro sintagma nominal pelo segundo sintagma nominal foi suficiente para desencadear a alteração das funções sintáticas sujeito e objeto e, como consequência, alterar o significado da primeira construção, já que nela o SN 'O menino', que desempenha a função sintática de sujeito e a função semântica de agente, na segunda construção passa a desempenhar a função sintática de Objeto e a função semântica de paciente.

Dessa maneira, marcação de caso, ordem e concordância podem atuar, cada um deles, em um sistema linguístico como o principal critério na delimitação de funções sintáticas ou podem atuar ao lado uns dos outros como em um sistema de compensação.

\section{Considerações Finais}

A análise da marcação de caso em Asurini do Xingu revela ser essa língua de estrutura ativo-estativa, havendo em sua estrutura ativa um sistema nominativoacusativo depreendido a partir do mecanismo referência cruzada. Já no sistema estativo, uma cisão, cisão-S, provocada pela morfossintaxe e pela semântica, faz surgir dois subtipos verbais: Sa, sujeito de sentença intransitiva ativa- cuja codificação se dá da 
mesma forma que A- e So, sujeito de sentença intransitiva estativa- cuja codificação se dá da mesma forma que $\mathrm{O}$.

Ao lado da marcação de caso, existem outros mecanismos que atuam também na identificação de sujeito e de objeto: a referência cruzada e a ordem. Na língua, surge ainda um outro padrão de concordância com morfema portmanteau, que será explorado em trabalho futuro dada a extensão deste trabalho, mas que já assinala para uma característica em comum com algumas línguas que usam afixos distintos para fazer referência a A e O, como algumas línguas da família tupi-guarani, entre elas Kamaiurá (Seki 2000) e Kaiowá (Cardoso 2008). Além disso, a língua apresenta também como mecanismo de codificação de sujeito e objeto uma hierarquia de pessoa que leva em conta a agentividade dos participantes do discurso na codificação dos argumentos sintáticos nucleares.

Dessa forma, o estudo das funções sintáticas nucleares em Asurini do Xingu, feito a partir de critérios formais amplamente utilizados nas descrições e análises das línguas em geral, revela ser a língua de estrutura ativo-estativo e mostra a importância que a semântica desempenha na gramática de uma língua, fazendo surgir novos padrões gramaticais decorrentes das necessidades linguísticas de seus usuários.

\section{REFERÊNCIAS}

CARDOSO, V. F. Aspectos Morfossintáticos da Língua Kaiowá (Guarani). Tese (Doutorado em Linguística) - Instituto de Estudos da Linguagem, Universidade Estadual de Campinas, Campinas, 2008.

COMRIE, B. Language universals and linguistic typology: Syntax and morphology. Chicago: Chicago University Pres, 1981.

COMRIE, B. Ergativity. In: WINFRED. P; LEHMAN (Org.). Syntactic typology.

Austin: University Press, 1978.

DIXON, R. M. W. Ergativity. Cambridge: Cambridge University Press, 1994.

DIXON, R. M. W. Ergativity. Language, n. 55, p. 59-138, 1979

GREENBERG, J. H. Some universals of grammar with particular reference to the order of meaningful elements. In: GREENBERG, J. H. (Ed.) Universals of language. Cambridge, Mass.: MIT Press, 1963. p. 73-113. 
HEWSON, J. Person hierarchies in Algokian and Inuktitut. Linguistic, n. 29, p. 861875, 1991.

MITHUM, M. Is basic word order universal? In coherence and Grounding in discurse. Ed. By Russel Tomli. Typological Studines in Language. John Benjamins, Amsterdam and Philadelphia. Vol. 11, p. 281-358, 1987.

PALMER, F. R. Grammatical roles and relations. Cambridge: Cambridge University Press, 1994.

PAYNE, T. E. Describing morphosyntax - a guide for field linguists. New York: Cambridge University Press, 1997.

PEREIRA, A. A. Estudo Morfossintático do Asurini do Xingu. Tese (Doutorado em Linguística) - Instituto de Estudos da Linguagem, Universidade Estadual de Campinas, Campinas, 2009.

PEREIRA, A. A. A nominalização e as orações relativas no Asurini do Xingu (Tupi-Guarani). LIAMES, Campinas, No. 10, P. 101-113, 2010.

RODRIGUES, A. D. Argumento e predicado em Tupinambá. In Boletin da associação brasileira de linguística, Vol. 19, p. 57-66, 1996.

RODRIGUES, A. D.; CABRAL, A. S . Revendo a classificação interna da família TupíGuaraní. In Cabral. Ana, Suely.; Rodrigues, Aryon. D. (Eds.). Línguas Indígenas Brasileiras. Fonologia, Gramática e História. Atas do I Encontro Internacional do GTLI da ANPOLL. Belém, 2002.

ROSE, F. Morphosyntaxe de L'emerillon: language tupí-guaraní de Guyane française. Tese (Doutorado), Université Lumière Lyon 2, França, 2003.

SEKI, L. Gramática do Kamaiurá: Língua tupí -guaraní do alto Xingu. Editora da Unicamp; São Paulo Imprensa Oficial, 2000.

SILVERSTEIN, M. Hierarchy of features and ergativity. In: DIXON, R.M.W (Org.). Gammatical categories in Australian languages. Camberra: Australian Ainstitut of Aboriginal Studies, 71-112, 1976.

QUEIXALÓS, F. (ed.) Des nomes e des verbes em Tupi- Guarani: état de la question. LINCOM Europa, München 2001

\section{Abreviaturas e convenções}


$A=$ Sujeito de verbo transitivo, Atr= Atributivo, Fem=Falante de sexo feminino, Excl= Exclusivo, Fut=Tempo futuro, Gn=Morfema genérico, Indf= Indefinido, Incl= Inclusivo, Mas=Falante de sexo masculino, Nom=Nominalizador, $\mathrm{N}=$ Nominalizador de argumento nuclear, $\mathrm{Neg}=\mathrm{Negação,} \mathrm{Npr}=$ Nome próprio, $\mathrm{O}=$ objeto, $\mathrm{Oi}=$ Objeto indireto, $\mathrm{P}=$ Objeto, Part.=Partícula, $\mathrm{Pl}=\mathrm{Plural}$, $\mathrm{Posp}=$ Posposição, $\mathrm{Q}=$ Interrogação, Refl=Reflexivo, Rel=Prefixo relacional, $S=$ Sujeito de verbo transitivo, $S a=$ Sujeito de verbo transitivo ativo, $\mathrm{SN}=$ Sintagma nominal, SNs Sintagmas nominais, So=Sujeito de verbo transitivo estativo, $\mathrm{Ve}=\mathrm{Verbo}$ estativo, $1=1$ a pessoa, $2=2$ a pessoa, $3=3 \mathrm{a}$ pessoa. 